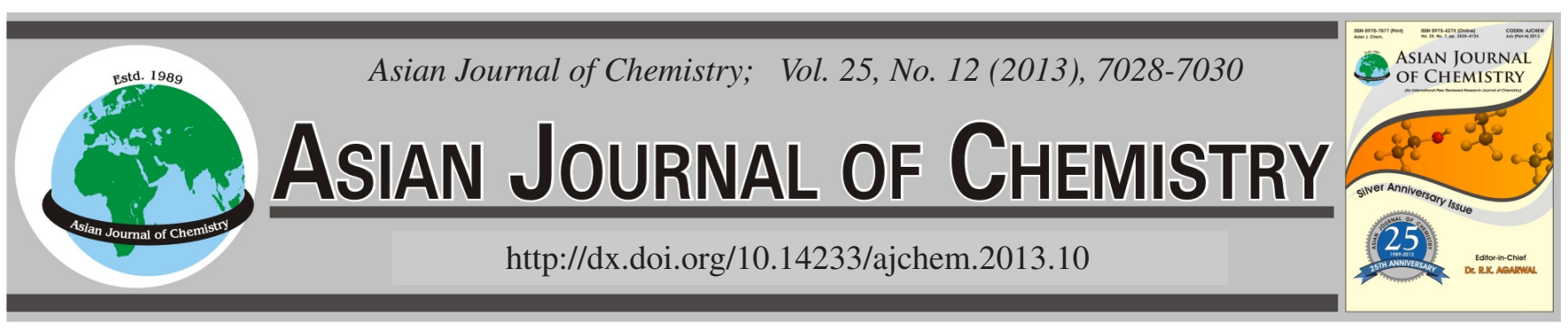

\title{
Electrical Conductivity Measurement of Molten Salts Using a Two-Electrode Alternative Current Impedance Method $\dagger$
}

Jong-Yun Kim*, Yong Suk Choi, Sang-Eun Bae, Ina Yum, Dae Hyeon Kim, Jei-Won Yeon and Kyuseok Song

Nuclear Chemistry Research Division, Korea Atomic Energy Research Institute, 989-111 Daedeok-daero, Yuseong-gu, Daejeon 305-353, Republic of Korea

*Corresponding author: Fax: +82 42 8688148; E-mail: kjy@ kaeri.re.kr

The electrical conductivity of molten salts was measured at various temperatures using a two-electrode AC impedance method. The conductivity of the LiCl-KCl molten salt was $1.87 \pm 0.01 \mathrm{~S} / \mathrm{cm}$ at $773 \mathrm{~K}$, which is the target temperature of the electrorefining process in the pyroprocess under development in Korea. The conductivity of the $\mathrm{LiCl}-\mathrm{KCl}$ molten salt increased with an increase in temperature. All conductivity data in the range between $650-850 \mathrm{~K}$ were consistent with the data predicted by the equation proposed in the literature.

Key Words: Electrical conductivity, Molten salt, Alternative current, Impedance analysis.

\section{INTRODUCTION}

High-temperature molten salt composed of a eutectic mixture of lithium chloride $(\mathrm{LiCl})$ and potassium chloride $(\mathrm{KCl})$ is used as a pyroprocess medium, which is actively under development in Korea, for the recycling of the nuclear spent fuels ${ }^{1-3}$. The physical properties of the molten salts are important in the operation of the process and modeling ${ }^{4,5}$. Electrical conductivity is one of the most important physical properties in the electrochemical pyroprocess ${ }^{6,7}$. Electrical conductivity gives information on the total ionic content. It is also closely related to the transport properties such as the mobility, diffusivity and viscosity as well as the current and energy efficiencies of the electrolytic processes.

Electrical conductivity measurements of molten salts have already been well documented for the harsh environments at high-temperatures with corrosive molten salts under an argon atmosphere without any moisture and oxygen to prevent undesired chemical reactions in a molten salt medium ${ }^{8}$. Both the AC and DC methods have been used to measure the electrical conductivity of high-temperature molten salts ${ }^{9,10}$. For the accurate conductivity measurement, an accurate cell constant value should be first determined based on an accurate measurement of the solution resistance of the conductivity standards at a specific temperature. The accuracy and precision of the cell constant depends strongly on the number and shape of the electrodes as well as the power supply mode. In principle, two, three, or four electrodes can be used with capillary or planar electrodes using an AC or DC supply. The high-temperature molten salt is a good example of a special application, since it contains an extremely high concentration of ions in the solutions. Due to the high conductivity of molten salts, a capillary electrode should be used instead of the ordinary planar electrode. Polarization is a major source of measurement error in the conductivity measurements. A four-electrode cell has a definite advantage over two- or three-electrode cells in terms of the polarization effect ${ }^{7}$. In addition, in order to avoid the polarization of the electrode in high-temperature and highconductivity molten salt, the AC method is known to be better than the DC method ${ }^{7,9}$. However, the reliability of the conductivity measurement method should be carefully examined in any case through the verification with the molten salt with a known conductivity value.

In this study, an AC impedance method with two capillary electrodes has been employed for an accurate determination of the resistance of the conductivity standard solutions and molten salt samples. The effect of high temperature on the cell constant, which is measured at much lower temperatures and on the resistance of molten salts might be serious and therefore, the conductivity values of $\mathrm{LiCl}-\mathrm{KCl}$ eutectic molten salts at $650-850 \mathrm{~K}$ has been compared with the literature values for a verification of our present method.

\section{EXPERIMENTAL}

In the electrical conductivity measurement system for the high-temperature molten salt, the furnace is attached to a dry

$†$ Presented to the 4th International Symposium on Applications of Chemical and Analytical Technologies in Nuclear Industries, Daejeon, Korea 
argon-filled glove box $\left(99.999 \% \mathrm{Ar}\right.$, both $\mathrm{H}_{2} \mathrm{O}$ and $\mathrm{O}_{2} \leq 1$ $\mathrm{ppm})$ and the temperature of the molten salt in the furnace was controlled using a $\mathrm{K}$ type thermocouple wire. A quartz vessel was placed inside the furnace. Anhydrous lithium chloride/potassium chloride $(\mathrm{LiCl}-\mathrm{KCl})$ eutectic mixture powder (99.99\% purity, $58 \mathrm{~mol} \% \mathrm{LiCl}$, Sigma-Aldrich) was loaded into the quartz tube and melted at $650-850 \mathrm{~K}$ under an argon atmosphere in the glove box.

For the measurement of the impedance of the solution, the in-house prepared dip-type capillary electrodes (Fig. 1) with two platinum wires were used with a Gamry potentiostat (Reference 600, Gamry Instruments, USA) at $291 \mathrm{~K}$ in the case of the conductivity standards and at $650-850 \mathrm{~K}$ for hightemperature molten salts. A very small sinusoidal AC voltage of $5 \mathrm{mV}$ was applied to the electrochemical cell in a frequency range of $50 \mathrm{~Hz}$ to $10,000 \mathrm{~Hz}$.

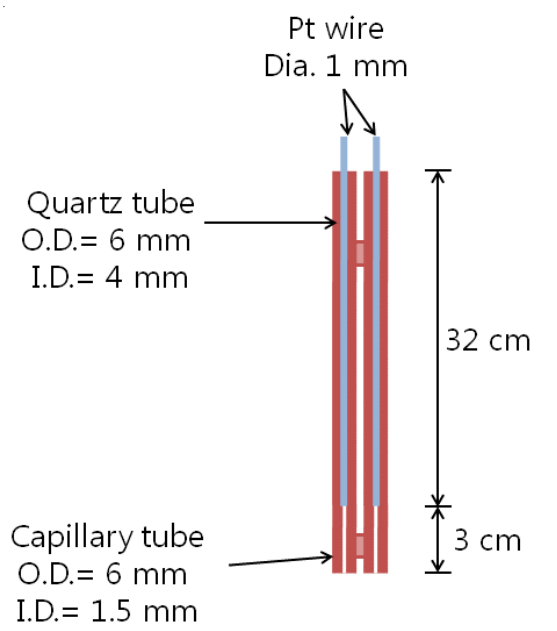

Fig. 1. Dip-type capillary electrode equipped with two platinum wires

In case of the determination of the cell constants, the above-prepared dip cell with two platinum wires was placed into the quartz vessel containing the conductivity standards. Five conductivity standard solutions of $0.001,0.01,0.1,1$ and $3 \mathrm{M} \mathrm{KCl}$ solutions with known conductivities (Table-1) were used as received from Fluka. The impedance of the five conductivity standard solutions was measured at $291 \mathrm{~K}$ in a water bath. For the conductivity measurement of molten salts, the same dip cell used in the determination of the cell constants was inserted into the quartz vessel containing the $\mathrm{LiCl}-\mathrm{KCl}$ molten salts.

\begin{tabular}{cc} 
TABLE-1 \\
CONDUCTIVITIES OF THE AQUEOUS KCL \\
SOLUTIONS AT 291 K \\
\hline $\mathrm{KCl}$ Concentration $(\mathrm{M})$ & Conductivity $(\mu \mathrm{S} / \mathrm{cm})$ \\
\hline 0.001 & 127.3 \\
0.01 & 1220.5 \\
0.1 & 11167 \\
1 & 97838 \\
3 & 266700 \\
\hline \\
\hline
\end{tabular}

Theoretical background of the AC impedance method: The resistance of an ionic solution depends on the ionic concentration, type of ions, temperature and the geometry of the electrochemical cell by the following relation.

$$
\mathrm{k}=\frac{1}{\rho}=\frac{\mathrm{L}}{\mathrm{A}} \times \frac{1}{\mathrm{R}}=\mathrm{C} \times \frac{1}{\mathrm{R}}
$$

where $\mathrm{k}$ is the solution conductivity $(\mathrm{S} / \mathrm{cm}), \rho$ is the solution resistivity, A is the area $\left(\mathrm{cm}^{2}\right)$ of each of the parallel electrodes, $\mathrm{L}$ is the distance $(\mathrm{cm})$ between two electrodes and $\mathrm{C}$ is the cell constant $\left(\mathrm{cm}^{-1}\right)$. An accurate measurement of the solution resistance is a key to an accurate determination of the cell constant and consequently the accuracy of the solution conductivity. The cell constant is determined directly by measuring the geometrical dimensions of the cell or by employing the conductivity standard solutions in the cell.

As with the resistance governed by the famous Ohm's law, impedance is a measure of the ability of a circuit to resist the flow of electrical current when a sinusoidal AC voltage is applied. The impedance of the electrochemical cell is represented as a complex number by the following equation analogous to Ohm's Law.

$$
\begin{aligned}
& Z(\omega)=\frac{E}{i}=\frac{E_{0} \sin (\omega t)}{i_{0} \sin (\omega t+\phi)}=Z_{0} \frac{\sin (\omega t)}{\sin (\omega t+\phi)} \\
& =Z_{0}(\cos \phi+j \sin \phi)=Z_{I m}+Z_{R e}
\end{aligned}
$$

where $Z_{0}$ is the magnitude and $\phi$ is a phase shift. In a Nyquist plot, $Z_{\mathrm{Re}}$, a real part of $\mathrm{Z}(\omega)$ is plotted on the $\mathrm{x}$-axis against an imaginary part $\left(\mathrm{Z}_{\mathrm{Im}}\right)$ in the $\mathrm{y}$-axis.

Many electrochemical cells can be represented by an equivalent electrical circuit that consists of the circuit elements such as resistors, capacitors and inductors in series and/or in parallel. In a Nyquist plot, the polarization correction is made by extrapolating to $\mathrm{Z}_{\mathrm{Im}} \rightarrow 0$ and the intercept of the curve with the real axis at the high-frequency region gives an estimate of the solution resistance.

Cell constants of capillary electrodes: In an AC conductivity measurement, the impedance is not purely resistive and other sources of impedance such as the Parker effect and the effect of a conducting thermostat medium should be considered on a top of the polarization correction ${ }^{11}$.

Fig. 2 is the Nyquist plot for $3 \mathrm{M} \mathrm{KCl}$ standard solution as a representative example. $\mathrm{Z}_{\mathrm{Im}}$ and $\mathrm{Z}_{\mathrm{Re}}$ for four conductivity

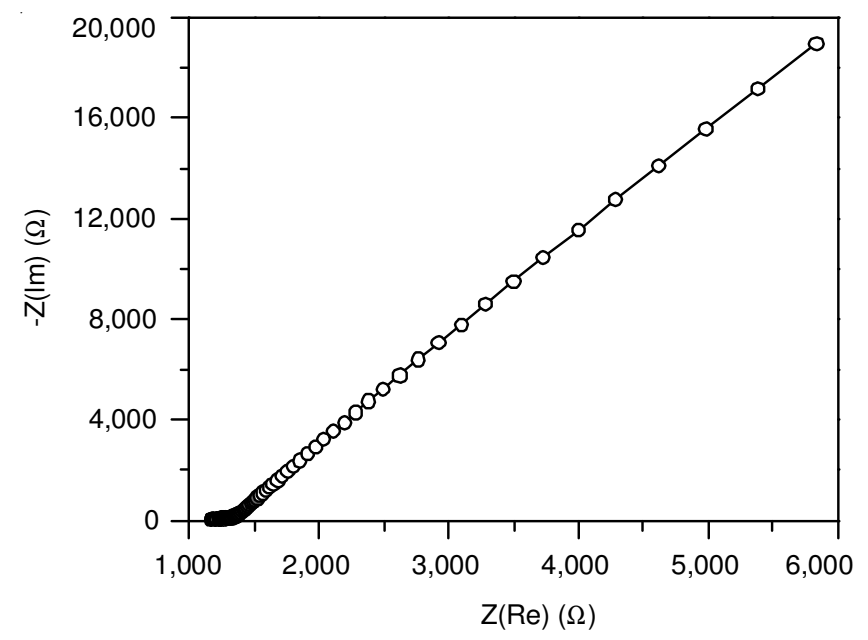

Fig. 2. A representative Nyquist plot for $3 \mathrm{M} \mathrm{KCl}$ solution at $291 \mathrm{~K}$ 
standards $(0.01,0.1,1$ and $3 \mathrm{M} \mathrm{KCl}$ solutions) show a linear correlation with the frequencies. For the $0.001 \mathrm{M} \mathrm{KCl}$ solutions, the solution resisivity is too high and therefore the solution resistance cannot be determined reliably as shown in Fig. 3. In such a case, the cell constant is too high to apply to the lowconductivity solution and the electrochemical cell should be re-designed in the direction to reduce the cell constant.

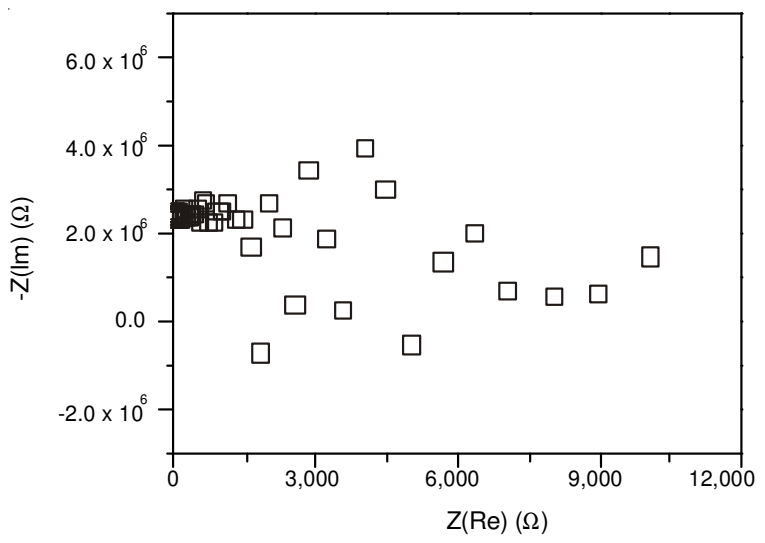

Fig. 3. Nyquist plot for $0.001 \mathrm{M} \mathrm{KCl}$ solution at $291 \mathrm{~K}$

Actually, the cell constant should remain constant regardless of the conductivities. However, in reality, it frequently does not remain constant owing to a variety of interferences. In particular, the molten salt contains lots of ions under hightemperature conditions and therefore there might be an effect of temperature or high concentration of ions on the cell constant. Fig. 4 shows that the cell constants of $0.01,0.1,1$ and $3 \mathrm{M}$ $\mathrm{KCl}$ solutions measured at $291 \mathrm{~K}$ were $304.9 \pm 0.3,311.3 \pm$ $0.9,309.5 \pm 0.4$ and $313.6 \pm 0.2 \mathrm{~cm}^{-1}$, respectively. It remained almost constant. The standard deviation among the test standard samples was only $4 \mathrm{~cm}^{-1}$ with an average cell constant of $310 \mathrm{~cm}^{-1}$.

Electrical conductivity of molten salts: In the experiment with the conductivity standards at $291 \mathrm{~K}$, the cell constant was not changed with the concentration of the ions, in other words, the conductivity of the ions in the solutions. However, the cell constant may change to a great extent with a large temperature variation. There is no primary standard for high-temperature molten salts. However, there are some

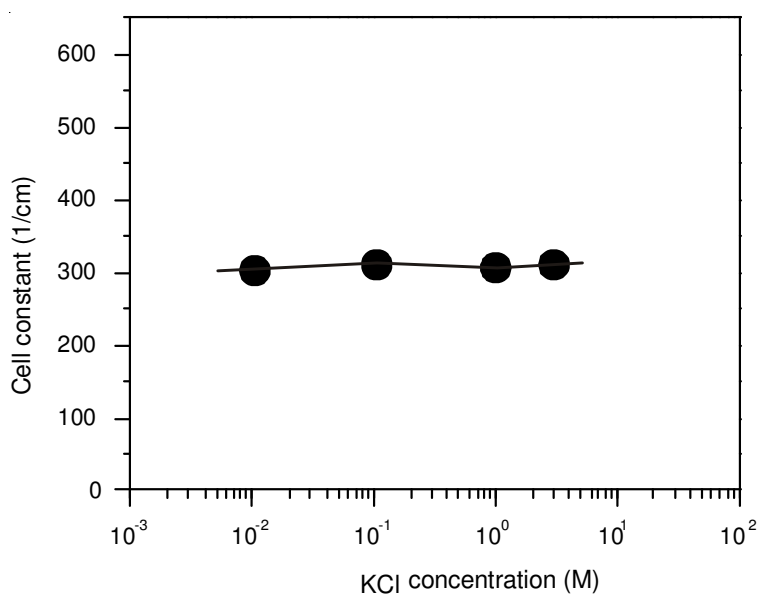

Fig. 4. Effect of the concentration of the conductivity standards on the cell constants conductivity data and the temperature-dependent equation is proposed as ${ }^{11}$.

$$
\mathrm{k}=\mathrm{a}+\mathrm{bT}+\mathrm{cT}^{2}
$$

where $\mathrm{a}=-5.6492, \mathrm{~b}=1.3732 \times 10^{-2}, \mathrm{c}=-5.1788 \times 10^{-6}$ and $\mathrm{T}$ is the temperature at the Kelvin scale for the eutectic containing $58.8 \mathrm{~mol} \% \mathrm{LiCl}$. Fig. 5 shows that the conductivity of LiCl$\mathrm{KCl}$ molten salt is consistent with the data predicted by eqn. (3) over a wide range of temperatures.

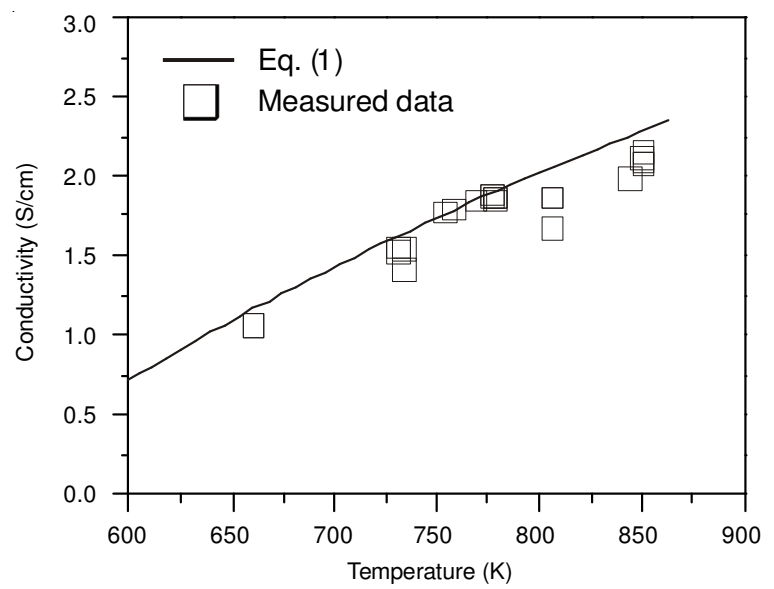

Fig. 5. Conductivity of $\mathrm{LiCl}-\mathrm{KCl}$ eutectic molten salts at various temperatures

\section{Conclusion}

The cell constant of the in-house prepared capillary cell was determined accurately as $310 \pm 4 \mathrm{~cm}^{-1}$. The accuracy of the cell constant determined using the conductivity standards was verified with $\mathrm{LiCl}-\mathrm{KCl}$ eutectic molten salt with known conductivity in a temperature range of 600-800 K.

\section{ACKNOWLEDGEMENTS}

This work was supported by the Nuclear Research and Development Program through National Research Foundation of Korea funded by the Ministry of Education, Science and Technology. The authors thank Mr. Heung Woo Kim for his wonderful glass work.

\section{REFERENCES}

1. H. Lee, G.-I. Park, K.-H. Kang, J.-M. Hur, J.-G. Kim, D.-H. Ahn, Y.-Z. Cho and E.H. Kim, Nucl. Eng. Technol., 43, 317 (2011).

2. H.S. Park, W.I. Ko, H.D. Kim, E.H. Kim and J.I. Kim, Prog. Nucl. Energy, 56, 91 (2012)

3. G.-S. You, I.-J. Cho, W.-M. Choung, E.-P. Lee, D.-H. Hong, W.-K. Lee and J.-H. Ku, Nucl. Eng. Design, 241, 415 (2011).

4. K.R. Kim, S.Y. Choi, D.H. Ahn, S. Paek, H.S. Lee and I.S. Hwang, J. Radioanal. Nucl. Chem., 286, 801 (2010).

5. S. Choi, J. Park, R.O. Hoover, S. Phongikaroon, M.F. Simpson, K.-R. Kim and I.S. Hwang, J. Nucl. Mater., 416, 318 (2011).

6. K. Matiasovsky, M. Malinovsky and V. Danek, Electrochim. Acta, 15, 25 (1970).

7. R.J. Guanti and P.J. Moran, J. Appl. Electrochem., 16, 678 (1986).

8. V. Danek, Physico-chemical Analysis of Molten Electrolyte. Elsevier B.V., Amsterdam, pp. 327-356 (2006)

9. E.R. Van Artsdalen and I.S. Yaffe, J. Phy. Chem., 59, 118 (1955).

10. F.R. Duke and L. Bissell, J. Electrochem. Soc., 111, 717 (1964).

11. G.J. Janz, R.P.T. Tomkins, C.B. Allen, J.R. Downey, Jr., G.L. Gardner, U. Krebs and S.K. Singer, J. Phys. Chem. Ref. Data, 4, 871 (1975). 